\title{
Application of computed tomography dose index as dosimetric parameter in dental tomography
}

\author{
Aplicação do indice de dose em tomografia computadorizada \\ como parâmetro dosimétrico em tomografia odontológica
}

Rodrigo Antonio Pereira MAURO1 ${ }^{1}$ https://orcid.org/0000-0003-4211-245X
Alessandro Martins da COSTA ${ }^{1}$ iD https://orcid.org/0000-0002-4621-0690

\section{ABSTRACT}

Objective: Quantify the CTDI from a reference beam, correcting this value for several beam widths from the ratio of CTDI ${ }_{100}$ values measured in the air, and verifying the underestimation of the dose comparing CTDI ${ }_{100}$ and $C T I_{300}$, applied to dental CBCT. Methods: i-CAT and Prexion 3D tomographs, $100 \mathrm{~mm}$ pencil ionization chamber, electrometer. Firstly for beam above $40 \mathrm{~mm}, \mathrm{CTDI}_{\mathrm{W}, \mathrm{NT}} \mathrm{from}$ $\mathrm{CTDI}_{\mathrm{W}, \mathrm{Re}}$, multiplied by the ratio of $\mathrm{CTDI}_{\mathrm{AR}}$ measurements to N.T widths and reference, was estimated. In second, CTDI ${ }_{100}$ and $C T D I_{300}$ are obtained by displacing the ionization chamber along the beam with spacing intervals equal to $100 \mathrm{~mm}$ to cover sufficiently large integration intervals for CBCT protocols, and a comparison is made through the modified efficiency. Results: CTDI ${ }_{A R, 100, R e f}$ averaged $53 \%$ higher than $\mathrm{CTDI}_{\mathrm{W}, \mathrm{Re}}$ due to attenuation of the beam by the simulator object, and the ratio between $\mathrm{CTDI}_{\mathrm{AR}, 100, \mathrm{Ref}}$ and $\mathrm{CTDI}{ }_{\mathrm{W}, \mathrm{Ref}}$ is greater than 1, being this constant relationship and validating the method for dosimetry in quality control tests. For the second method, CTDI $_{100}$ greatly underestimates the dose deposited on the central axis, where CTDI $_{300}$ covers all beam sizes and stands out in relation to $\mathrm{CTDI}_{100}$ to more accurately quantify the radiation levels emitted. Conclusion: The IEC method is applicable to quality control, facilitating practice, and optimizing time and resources. CTDI ${ }_{300}$ is a better dose descriptor than CTDI ${ }_{100}$, and should be implemented for CBCT modalities when used.

Indexing terms: Cone-beam computed tomography. Dentistry. Dosimetry. Radiography.

\section{RESUMO}

Objetivo: Quantificar o CTDI a partir de um feixe de referência, corrigindo este valor para diversas larguras de feixe a partir da razão dos valores CTDI 100 medidos no ar e verificar a subestimação da dose comparando o CTDI ${ }_{100}$ e CTDI ${ }_{300}$ aplicados à CBCT odontológica. Métodos: Tomógrafos i-CAT e Prexion 3D, câmara de ionização de 100mm tipo lápis, eletrômetro. Primeiramente para feixes acima de 40mm, estimou-se o CTDI ${ }_{W, N T}$ a partir do CTDI ${ }_{W, R e f}$ multiplicado pela razão das medidas do CTDI ${ }_{A R}$ para larguras N.T e referência. Em segundo, CTDI 100 e CTDI ${ }_{300}$ são obtidos deslocando-se a câmara de ionização ao longo do feixe com intervalos de espaçamento igual a $100 \mathrm{~mm}$ para cobrir intervalos de integração suficientemente grandes para protocolos CBCT e uma comparação é realizada através da eficiência modificada. Resultados: O CTDI ${ }_{A R, 100, R e f}$ foi em média 53\% maior que o CTDI ${ }_{W, \text { Ref }}$ devido a este atenuar o feixe pelo objeto simulador, e a razão entre o $C T D I_{A R, 100, \text { Ref }}$ e CTDI ${ }_{W, \text { Ref }}$ é maior que 1, sendo essa relação constante e validando o método

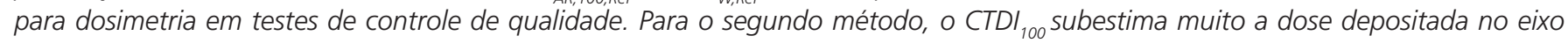

$\boldsymbol{\nabla} \mathbf{v} \mathbf{v}$

1 Universidade de São Paulo, Faculdade de Filosofia Ciências e Letras de Ribeirão Preto, Departamento de Física. Av. Bandeirantes 3900 , 14040901, Monte Alegre, Ribeirão Preto, SP, Brasil. Correspondence to: RAP MAURO. E-mail: <rodrigomauro@usp.br>.

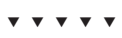

Mauro RAP, Costa AM. Dose index in dental tomography. RGO, RGO, Rev Gaúch Odontol. 2021;69:e2021008. http://dx.doi.org/10.1590/198186372021000820180112 
central, onde o CTDI ${ }_{300}$ abrange todos os tamanhos de feixe e se destaca em relação ao CTDI ${ }_{100}$ para quantificar com maior exatidão os níveis de radiação emitidos. Conclusão: O método IEC é aplicável para controle de qualidade, facilitando a prática, e otimizando tempo e recursos. O CTDI 300 é um melhor descritor de dose que o CTDI ${ }_{100}$ e deve ser implementado para modalidades CBCT quando usados.

Termos de indexação: Tomografia computadorizada de feixe cônico. Odontologia. Dosimetria. Radiografia.

\section{INTRODUCTION}

Computed tomography (CT) is an important diagnostic technique, used directly to obtain diagnoses or indirectly to aid other techniques such as radiotherapy and nuclear medicine. It is a technique that is based on the volumetric construction of a body region from projections of two-dimensional images around the body, which directly results in a higher dose deposition in the organs compared to conventional techniques. Thus, the radioprotection of individuals must be optimized to minimize the risks of adverse effects to health [1-4]. The establishment and application of a quality control routine aims to ensure that all machine and radiation exposure parameters are maintained in accordance with the well known As Low As Reasonably Achievable (ALARA) principle. Ensure maximum performance with minimal dose deposition in the patient. In order to guarantee this principle, some CT performance descriptors are known, such as the Computed Tomography Dose Index (CTDI), which quantify the dose in the imaged region [5]. The first CT scanners (single slice) had a beam collimation of up to $10 \mathrm{~mm}$. However, the technological evolution of this diagnostic technique brought multislice tomography, with beam widths up to 40 $\mathrm{mm}$, helical tomography and conical beam tomography. Due to this development of new techniques and the consequent increase in beam width, it became necessary to adapt the CTDI. Several descriptors then emerged, such as $\mathrm{CTDI}_{\mathrm{FDA}^{\prime}}, \mathrm{CTDI}{ }_{100^{\prime}}, \mathrm{CTDI}_{\mathrm{W}^{\prime}}, \mathrm{CTDI} \mathrm{vol}_{\mathrm{vo}}$ and the Dose Length Product (DLP) [6]. The CTDI ${ }_{100}$ was developed to quantify the useful dose output for a single beam rotation over a length of $100 \mathrm{~mm}$ of a pencil lonization Chamber (IC), located in the isocenter and parallel to the tomography longitudinal axis. The application of the concept of CTDI 100 measurements performed on a phantom consisting of polymethylmethacrylate (PMMA), simulating a head with a length of $15 \mathrm{~cm}$ and a diameter of $16 \mathrm{~cm}$ and simulating a chest with a length of $15 \mathrm{~cm}$ and a diameter of $32 \mathrm{~cm}$, gives rise to $\mathrm{CTDI}_{\mathrm{PMMA}, 100}$. However, the use of $\mathrm{CTDI}_{100}$ has shown a great limitation, particularly for large beams, in which measurements are underestimated because they do not take scattered radiation into account. In addition to the techniques already mentioned, consideration should be given to the dental Cone Beam Computed Tomography (CBCT), which covers irradiated lengths of $230 \mathrm{~mm}$ in just one rotation of the $\mathrm{X}$-ray tube, which illustrates that the dosimetric parameters for this type of tomography must, in particular, be reviewed and modified. Several approaches to overcome this limitation of CTDI 100 were proposed by the International Electrotechnical Commission (IEC) [7] and the American Association of Physicists in Medicine (AAPM) [8]. One of the approximations of the IEC aims at quantifying the CTDI from a reference beam and correcting this value for other beam widths from the ratio of measured values in air to the CTDI ${ }_{100}$. This approach was recommended by the International Atomic Energy Agency (IAEA) [9]. The IAEA also suggests another approximation to quantify the free CTDI in the air $\left(C T D I_{A R}\right)$, this variation applies to beams larger than $60 \mathrm{~mm}$ and is strictly measured in the air, where IC displacements can be performed to encompass the entire primary and scattered beam [9].

Discussions have been conducted between the use or not of CTDI or other dosimetric quantity $[10,11]$. The main limitation of the CTDI is its integration length of $100 \mathrm{~mm}$, too short to encompass the entire scattered radiation generated by a CBCT unit; another limitation is the difference of the CTDI and the DLP, as the CTDI is the DLP divided by the beam thickness, however, if a protocol with a height of $13 \mathrm{~cm}$ is used, the scanned height is greater than the length of the chamber, i.e., the primary beam and the entire scattered tail will not be counted, and dividing the DLP by the beam thickness, a completely wrong dose descriptor is obtained. Mori et al. [12] and Loubele et al. [13] mention that the use of longer phantoms is impossible in dentomaxillofacial applications. Loubele et al. [13] also conclude that the utilization of DLP is the most appropriate, since the dose measured by the length of the ionization chamber integration depends on the beam thickness.

Several studies are being performed using another dosimetric parameter, the Product Kerma Air-area $\left(\mathrm{P}_{\mathrm{KA}}\right)$, as the incident Kerma is measured and multiplied by the 
beam area in the detector [14-18]. This method does not require phantom, or possible IC displacements, since the detector is of parallel plates and can measure directly or indirectly the $\mathrm{P}_{\mathrm{KA}}$, so a $\mathrm{P}_{\mathrm{KA}}$ meter can be positioned just after the beam output, measuring all the radiation that can be received by the patient. It is a widely used method, and studies to define a global diagnostic reference parameter, applicable to dental tomography, are still under way.

In this study the applicability of the method suggested by the IEC and also the underestimation of the dose using the method proposed by the IAEA using the $\mathrm{CTDI}_{100}$ and $\mathrm{CTDI}{ }_{300}$, applied to dental CBCT.

\section{METHODS}

The data were obtained from dental radiology clinics in the city of Ribeirão Preto, state of São Paulo. This research is quantitative experimental, with continuous variable and cross-sectional design. The dose values obtained were corrected for temperature and atmospheric pressure at reading, thus avoiding possible variations due to air density in the sensitive volume of the chamber.

The dosimeter used consists of a pencil ionization chamber of $100 \mathrm{~mm}$ length, $3.14 \mathrm{~cm}^{3}$ sensitive volume, PTW FREIBURG, model TN30009-0507, and an electrometer PTW FREIBURG, model UNIDOS E. The tomographic equipment studied was i-CAT Classic manufactured by Imaging Sciences International and Prexion 3D manufactured by Prexion.

In order to evaluate the dose delivered by the dental $C B C T$, in which the Field Of View (FOV) size may reach $23 \mathrm{~cm}$ [19] of height for face acquisition protocols, the methodology suggested by the IEC [7] and the IAEA dosimetry protocol [9] was utilized, which considers for beams above $40 \mathrm{~mm}$ thick that the $\mathrm{CTDI}_{\mathrm{W}, \mathrm{NT}}$ can be estimated from reference measures on the phantom corrected by the ratio of the measurements of the CTDI ${ }_{A R}$.

$$
\text { Defining the } \mathrm{CTDI}_{100} \text { as: }
$$

$$
C T D I_{100}=\frac{1}{N \times T} \int_{-50 m m}^{50 m m} D(z) d z
$$

Where $\mathrm{N}$ is the number of slices acquired in a single rotation, $T$ is the nominal thickness of a slice, $D(z)$ is the profile of Kerma in air at the z position. Measurements of the $\mathrm{CTDI}_{100}$ in a phantom performed at the center and periphery, take into account the heterogeneity of the
Kerma distribution through the phantom, thus defining the weighted CTDI (Weighted) or CTDI ${ }_{w}$ as:

$$
C T D I_{W}=\frac{1}{3} C T D I_{100, c}+\frac{2}{3} C T D I_{100, p}
$$

Where CTDI ${ }_{100, c}$ is measured in the central cavity of the phantom, and CTDI ${ }_{100, p}$ is calculated as the arithmetic mean of the four measurements obtained at the periphery [20].

Then for beams larger than $40 \mathrm{~mm}$, the $\mathrm{CTDI}_{\mathrm{w}}$ can be written as:

$$
C T D I_{W, N T}=C T D I_{W, R e f} \times\left(\frac{C T D I_{a r, 100, N T}}{C T D I_{a r, 100, R e f}}\right)
$$

Where $C T D I_{W, N T}$ is measured on the phantom for beam width N.T, when N.T $>40 \mathrm{~mm} ; \mathrm{CTDI}_{\mathrm{W}, \text { Ref }}$ is measured on the phantom for reference beam width $20 \mathrm{~mm}$ or less, $\mathrm{CTDI}_{\mathrm{AR}, 100, \mathrm{NT}}$ and $\mathrm{CTDI}_{\mathrm{AR}, 100, \mathrm{Ref}}$ are measured in air for the integration length of the ionization chamber of $100 \mathrm{~mm}$, at a beam width of any N.T and of reference respectively $[9,21]$. The ratio between the indices in air is considered to be equal to the ratio for the indices measured in the phantom.

The IAEA also presented a methodology to measure the radiation dose profile in the air for tomography units that use beams larger than $60 \mathrm{~mm}$. An approximation is made around the $100 \mathrm{~mm} \mathrm{IC}$. To achieve longer integration lengths, the ionization chamber is moved along the beam (symmetrically) at $100 \mathrm{~mm}$ spacing intervals, as shown in figure 1, where a measurement is performed at each position in a continuous manner, without interposition of the sensitive volume. In the case of interposition, the measured beam interval twice shall be taken into consideration in the final calculation.

If the displacements are continuous equal to the length of the IC, the total dose integral is the sum of a series of measurements along the beam described below:

$$
C T D I_{A R}=\frac{1}{N x T} \times \sum_{i=1}^{i=n}\left[\int_{0}^{L_{c}} D_{i}(z) d z\right]
$$

Where $\mathrm{N}$ is the number of steps taken along the beam [9]. It should be noted that this method is implemented in the z-axis and does not report an axial dose distribution as in $\mathrm{CTDI}_{\mathrm{W}, 100}$, as no measurements are performed in the periphery of the FOV, is a one-dimensional measure of profile that aims at efficient beam coverage and does not take into account scattered radiation, which in 


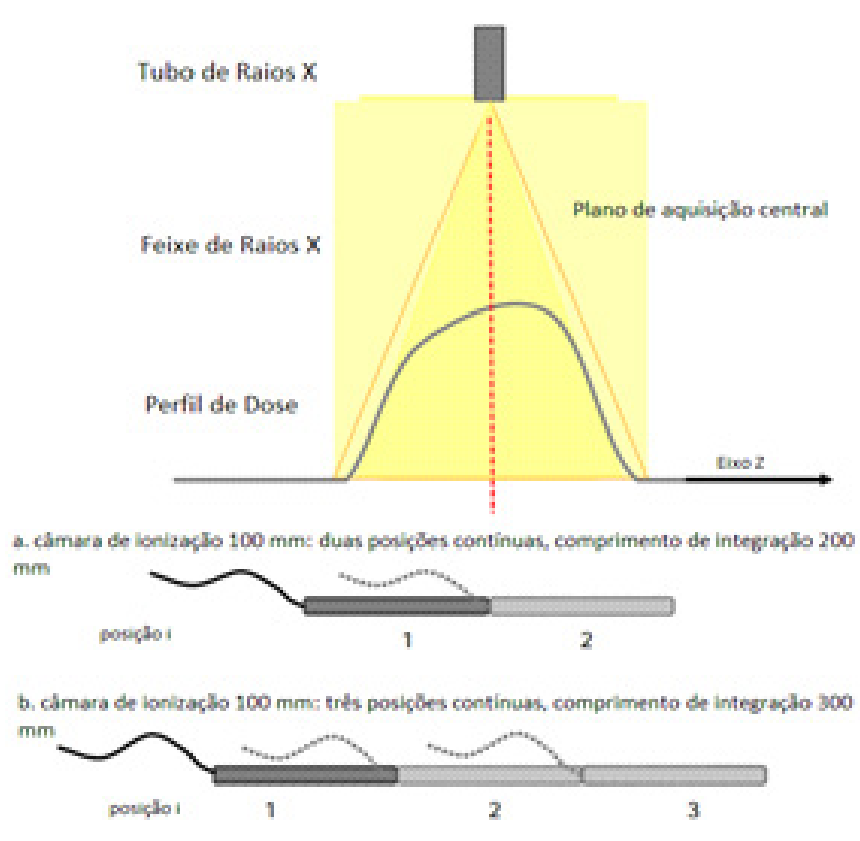

Figure 1. Diagram showing increments equal to the length of the chamber. The beam dose profile is heterogeneous. In case (a) there is a dose integration length of $200 \mathrm{~mm}$, and in case (b) there is an integration length of $300 \mathrm{~mm}$. Longer lengths can be obtained [21].

the case of air is irrelevant. Larger cameras such as $300 \mathrm{~mm}$ pencil IC, solid state detectors and thimble type IC can be used for this methodology, provided they are calibrated for the beam spectrum in question. The experiment measured the values of $C T D I_{100}$ and $C T D I_{300}$. This methodology was used for i-CAT and Prexion 3D equipment. Using the values found and applying the above methodology, and giving prominence to the limitation of $\mathrm{CTDI}_{100}$, which does not cover the entire radiation beam that contributes to the dose in the patient, we use the concept of efficiency $(\varepsilon)$, which is the ratio of $C T D I_{A R^{\prime}} 100$ and $C T D I_{\infty}$ (integrated dose on $z$ axis with infinite integration limits), which can be used as an indicator of ability, or even the capacity of CTDI ${ }_{100}$ to represent the full dose values received by the patient.

$$
\mathcal{E}=\frac{C T D I_{100}}{C T D I_{\infty}}
$$

Where $C T D I_{\infty}$ is equal to:

$$
\overline{C T D I_{\infty}}=\frac{1}{N \times T} \int_{-\infty}^{\infty} D(z) d z
$$

However, since an infinite ionization chamber, physically impossible, was not available, a finite integration length of $300 \mathrm{~mm}$ was used in place of the, feasible due to the application of the displacement method. Thus the modified efficiency $\left(\varepsilon_{m}\right)$ can be obtained as:

$$
\varepsilon_{m}(C T D I)=\frac{C T D I_{100}}{C T D I_{300}}
$$

This parameter directly brings a relative comparison between the dose values, varying the limits of integration.

\section{RESULTS}

The protocols available for i-CAT Classic equipment have three mAs configurations (mili-Ampère second), so for each configuration equation 3 was applied.

In table 1 are represented the $C T D I_{W, N T}$ values calculated

\begin{tabular}{|c|c|c|}
\hline \multicolumn{3}{|c|}{ i-CAT Classic } \\
\hline $16 \times 6 \mathrm{~cm}, 40 \mathrm{~s}, 36.12 \mathrm{mAs}$ & $3.80 \pm 0.15$ & $5.16 \pm 0.49$ \\
\hline $16 \times 6 \mathrm{~cm}, 20 \mathrm{~s}, 18.45 \mathrm{mAs}$ & $1.89 \pm 0.10$ & $2.42 \pm 0.11$ \\
\hline $16 \times 6 \mathrm{~cm}, 10 \mathrm{~s}, 9.65 \mathrm{mAs}$ & $0.99 \pm 0.10$ & $1.23 \pm 0.15$ \\
\hline Protocol & $\mathrm{CTDI}_{\mathrm{W}, \mathrm{NT}}(\mu \mathrm{Gy})$ & $\mathrm{CTDI}_{\mathrm{AR}, 100, \mathrm{NT}}(\mu \mathrm{Gy})$ \\
\hline $16 \times 8 \mathrm{~cm}, 20 \mathrm{~s}, 18.45 \mathrm{mAs}$ & $2.09 \pm 0.18$ & $2.68 \pm 0.11$ \\
\hline $16 \times 8 \mathrm{~cm}, 10 \mathrm{~s}, 9.5 \mathrm{mAs}$ & $0.97 \pm 0.16$ & $1.20 \pm 0.11$ \\
\hline $16 \times 13 \mathrm{~cm}, 40 \mathrm{~s}, 36.12 \mathrm{mAs}$ & $3.93 \pm 0.44$ & $5.33 \pm 0.10$ \\
\hline $16 \times 13 \mathrm{~cm}, 20 \mathrm{~s}, 18.45 \mathrm{mAs}$ & $2.12 \pm 0.16$ & $2.71 \pm 0.16$ \\
\hline $16 \times 13 \mathrm{~cm}, 10 \mathrm{~s}, 9.65 \mathrm{mAs}$ & $1.10 \pm 0.16$ & $1.37 \pm 0.06$ \\
\hline
\end{tabular}
from equation 3 , using the nominal values of beam width

Table 1. CT dose index. 
N.T, in which case, the height of FOV is taken, representing the nominal value N.T. The ratio of the measured dose indices in air to the reference width and to the width N.T in question, represent with almost no discrepancy, the same ratio when calculated on the phantom.

Table 2 shows the results for $C T D I_{100}$ and $C T D I_{300}$ measured in a head phantom.

Table 3 shows the results for $\mathrm{CTDI}_{\mathrm{AR}, 100}$ and $C T D I_{A R, 300}$ measured in the air. It can be observed from the table that $C T D I_{A R, 100}$ reached $69 \%$ on average of the values found for $C T D I_{A R, 300}$, and the smallest discrepancy was found for Prexion 3D.

\section{DISCUSSION}

Observing in general the data in table 1 , it is visible that $\mathrm{CTDI}_{\mathrm{AR}, 100, \text { Ref }}$ is on average $53 \%$ larger than $\mathrm{CTDI}_{\mathrm{W}, \mathrm{Re}^{\prime}}$ which can be justified by the latter being measured with phantom in position, being responsible for the attenuation and scattering of the X-ray beam between the detector and the source and also filtering the low energy photons, which do not interact with the IC, whereas the CTDI ${ }_{A R, 100, \text { Ref }}$ only the primary beam contributes to the reading. The application of the method proposed by equation 3 facilitates the routine dosimetry of the equipment, since the reference CTDI is estimated only once and the measurements of the CTDI in air are easily realized readings in clinical practice.

One limitation found in the application of this method was the reference width N.T, which should be less than or equal to $2 \mathrm{~cm}$, width that is not found in any of the available dental CT scanners on the market, with the minimum nominal width available being $5 \mathrm{~cm}$. Thus, this study considered as minimum reference width, the lowest beam width available in the protocols of each equipment used, for i-CAT and Prexion of $6 \mathrm{~cm}$ and $5 \mathrm{~cm}$, respectively. In table 1, the ratio between $C T D I_{A R, 100, \text { Ref }}$ and $C T D I_{W, \text { Ref }}$ is greater than 1 due to the methodological difference of each measure previously discussed, this ratio is maintained for different acquisition protocols and represents the proportion for any desired N.T. In this way, the procedure

Table 2. Modified efficiency in the phantom.

\begin{tabular}{lccc}
\hline & \multicolumn{3}{c}{ i-CAT Classic } \\
\hline Protocol & CTDI $_{100}(\mu \mathrm{Gy})$ & CTDI $_{300}(\mu \mathrm{Gy})$ & $\varepsilon_{\mathrm{m}}(\mathrm{CTDI})$ \\
\hline $16 \times 6 \mathrm{~cm}, 40 \mathrm{~s}, 36.12 \mathrm{mAs}$ & $4.02 \pm 0.15$ & $6.76 \pm 0.17$ & 0.59 \\
$16 \times 6 \mathrm{~cm}, 20 \mathrm{~s}, 18.45 \mathrm{mAs}$ & $2.00 \pm 0.10$ & $3.20 \pm 0.11$ & 0.62 \\
$16 \times 6 \mathrm{~cm}, 10 \mathrm{~s}, 9.65 \mathrm{mAs}$ & $1.04 \pm 0.10$ & $1.66 \pm 0.10$ & 0.63 \\
\hline
\end{tabular}

Table 3. Modified efficiency in air

\begin{tabular}{|c|c|c|c|}
\hline \multicolumn{4}{|c|}{ i-CAT Classic } \\
\hline Protocol & $\mathrm{CTDI}_{\mathrm{AR}, 100}(\mu \mathrm{Gy})$ & $\mathrm{CTDI}_{\mathrm{AR}, 300}(\mu \mathrm{Gy})$ & $\varepsilon_{\mathrm{m}}(\mathrm{CTDI})$ \\
\hline $16 \times 6 \mathrm{~cm}, 40 \mathrm{~s}, 36.12 \mathrm{mAs}$ & $5.15 \pm 0.49$ & $7.16 \pm 0.54$ & 0.72 \\
\hline $16 \times 6 \mathrm{~cm}, 10 \mathrm{~s}, 9.65 \mathrm{mAs}$ & $1.23 \pm 0.15$ & $1.71 \pm 0.17$ & 0.72 \\
\hline $16 \times 8 \mathrm{~cm}, 40 \mathrm{~s}, 36.12 \mathrm{mAs}$ & $5.35 \pm 0.10$ & $7.48 \pm 0.16$ & 0.72 \\
\hline $16 \times 13 \mathrm{~cm}, 40 \mathrm{~s}, 36.12 \mathrm{mAs}$ & $5.33 \pm 0.10$ & $7.44 \pm 0.13$ & 0.72 \\
\hline $16 \times 13 \mathrm{~cm}, 20 \mathrm{~s}, 18.45 \mathrm{mAs}$ & $2.71 \pm 0.16$ & $3.79 \pm 0.08$ & 0.72 \\
\hline $16 \times 13 \mathrm{~cm}, 10 \mathrm{~s}, 9.65 \mathrm{mAs}$ & $1.37 \pm 0.06$ & $1.92 \pm 0.08$ & 0.71 \\
\hline $16 \times 22 \mathrm{~cm}, 40 \mathrm{~s}, 36.9 \mathrm{mAs}$ & $4.10 \pm 0.06$ & $7.74 \pm 0.10$ & 0.53 \\
\hline
\end{tabular}


can be applied as a tool to practice dosimetry in quality control tests for dental tomography.

Abuhaimed et al. [22] have evaluated the efficiency of dosimetry methods (CTDI) for CBCT by Monte Carlo and results with efficiency between $74 \%$ and $41 \%$ were verified for head acquisition protocols. There is a variation of the values of $\mathrm{\varepsilon m}$ in relation to the beam width, the greater the width, the lower the efficiency, very clear behavior, analyzing the definition of $\varepsilon$. The IEC has modified the definition of the free CTDI in air, mainly in relation to the integration limits, where these should not be less than $100 \mathrm{~mm}$. For beams with a width of $60 \mathrm{~mm}$ or more, the integration limits should be calculated by adding $40 \mathrm{~mm}$ beyond the nominal width, i.e., a $20 \mathrm{~mm}$ edge is added on each side of the beam profile as: (N.T) $+40 \mathrm{~mm}$. And if the beam width is less than $60 \mathrm{~mm}$, the fixed integration limits are maintained at $100 \mathrm{~mm}$ [23].

The dose values obtained from $\mathrm{CTDI}_{A \mathrm{R}^{\prime}}$ with integration lengths of $100 \mathrm{~mm}$ and $300 \mathrm{~mm}$, were compared with the objective of verifying the modified efficiency between these two parameters, which may influence the effective dose values, when conversion factors for effective dose are used [24,25]. Evaluating the data in table 2, note that CTDI 100 is on average $61.3 \%$ of the measured values for $\mathrm{CTDI}_{300}$, thus, a remarkable underestimation of the dose is presented by CTDI100, this leads to the conclusion that the dose profile integral for a length of $300 \mathrm{~mm}$ completely and efficiently covers the beam dimensions for dental $C B C T$, including scattered radiation $[24,26]$. Observing the data in table 3 with CTDI measured in air, note that CTDI ${ }_{A R, 100}$ is on average $72 \%$ of $\mathrm{CTDI}_{\mathrm{AR}, 300}$, for FOV up to $13 \mathrm{~cm}$ high, and $53 \%$ for FOV 22 $\mathrm{cm}$ high of i-CAT equipment and $83 \%$ for Prexion 3D. The acquisition protocol 16x22 cm, 40 s, 36.9 mAs, from Table 3, calibrated for i-CAT equipment, presented CTDI ${ }_{A R, 100} 53 \%$ of $C T D I_{A R, 300}$, this is due to the size of the FOV in the parallel direction to the IC being $22 \mathrm{~cm}$, and CTDI ${ }_{A R, 100}$ measured over a length of $100 \mathrm{~mm}$. Use linear displacement of the IC to cover $30 \mathrm{~cm}$ of dose integration, covers the entire beam, and with margins of $4 \mathrm{~cm}$ left on each side of the profile, but when using protocols with smaller beam widths, the difference between the CTDI decreases, because the closer the beam width to $100 \mathrm{~mm}$, the closer the modified efficiency will be. In routine dosimetry, all these protocols are being underestimated in their dose values received by the patient, so the specialist responsible for quality control should be attentive to the variables that influence dosimetry, know the geometric parameters of the primary beam, such as width and symmetry, type of rotation of the $x$-ray tube and appropriate collimation. By the definition of CTDI, the dose integral is one-dimensional, and takes into account primary and secondary radiation. The values obtained in this experiment only report estimates of the amount of radiation that the equipment in question can deliver to the patient, which suggests that the CTDI ${ }_{300}$ presents a value of the most complete dose estimate for large beams. The immediately higher and lower measured dose values in relation to the central position of the beam place dose in the upper cranial cap and neck, where the thyroid is located, one of the radiosensitive organs present in the human body. CTDI does not take into account any risk factor or radiosensitivity of the irradiated tissue.

This study was applicable only to two CT scanners that allowed the correct positioning of the phantom through the X-ray beam. The limiting problem for this methodology presented, including the measurement of $\mathrm{CTDI}_{300}$, was implemented in quality control in a dental radiology clinic, it is the variety of types of patient positioning during the acquisition, which are different between manufacturers. There is the possibility of acquisition standing or seated. The tomographs studied perform acquisition with the patient seated. Already, other tomographs like Eagle 3D manufactured by Dabi Atlante and OP300 manufactured by Instrumentarium, need an immobilizer support for the chin, because the patients are positioned standing, and because of this, this immobilizer support is very close to the edges of the beam, preventing the positioning of the phantom and limiting the displacements of the IC when necessary

\section{CONCLUSION}

Two methods of evaluation of dose levels were presented in order to evaluate the efficacy of the methodology presented, as well as the accuracy of dose values when comparing the limits of integration of 100 and $300 \mathrm{~mm}$. Based on the data, the method presented by the IEC proved to be reproducible, with good repetitivity of correction factors by the ratio of measurements in the air, so a quality control practice can be aided by this methodology, seeking the optimization of time and available resources.

Even with some limitations of the practice in complying with the theory, it was possible to observe, 
therefore, the easy application of formalities and obtaining the results, countering this ease with the impossibility of applying it to the other tomographs, which perform acquisition standing, a negative point in the use of CTDI as a dosimetric parameter for $C B C T$, since the vast majority of dental tomography apparatuses in Brazil are positioning erected.

A relative comparison through the modified efficiency as calculated above showed a large discrepancy of the measured dose values with integration limits of 100 and $300 \mathrm{~mm}$, therefore, for CBCT dosimetry it is necessary to use longer integration lengths, avoiding underestimation of the dose.

Some study and research trends point to more complete and reliable dosimetric parameters for $\mathrm{CBCT}$, sensitive to exposure factors, and also size and geometry of FOV. The PKA is an option that has been widely discussed, as a reference quantity.

Thus, doubt remains and a very valid question when it takes the radioprotection of the patient in question, should the CTDI still be used, being such an antiquated parameter, amid new and diverse technologies? Always, patient safety is the primary issue and the main objective in any and all radiological practice.

\section{Collaborators}

The author RAP MAURO, performed the field research, collecting data from each equipment to then analyze and discuss the results. AM COSTA, assisted in data analysis and discussion, seeking correlations with current dosimetry practices and their effectiveness in daily practice.

\section{REFERENCES}

1. Brenner DJ, Hall EJ. Computed tomography - An increasing source of radiation exposure. N Engl J Med. 2007;169(22):2277-84. https://dx.doi.org/10.1056/NEJMra072149

2. Smith-Bindman R, Lipson J, Marcus R, Kim K-P, Mahesh M, Gould R, et al. Radiation dose associated with common computed tomography examinations and the associated lifetime attributable risk of cancer. Arch Intern Med. 2009;169(22):2078-86. https://dx.doi.org/10.1001/archinternmed. 2009.427

3. Brenner DJ, Shuryak I, Einstein AJ. Impact of reduced patient life expectancy on potential cancer risks from radiologic imaging. Med Phys. 2011;261(1):193-8. https://dx.doi. org/10.1001/archinternmed.2009.427
4. Pearce MS, Salotti JA, Little MP, McHugh K, Lee C, Kim $\mathrm{KP}$, et al. Radiation exposure from CT scans in childhood and subsequent risk of leukaemia and brain tumours: A retrospective cohort study. Lancet. 2012;380(9840):499-505. https://dx.doi.org/10.1001/archinternmed.2009.427

5. Shope TB, Gagne RM, Johnson GC. A method for describing the doses delivered by transmission x-ray compute tomography. Med Phys. 1981;8(4):488-95. https://dx.doi.org/10.1118/1.594995

6. McNitt-Gray MF. AAPM/RSNA physics tutorial for residents: Topics in CT. RadioGraphics. 2002;22(6):1541-53. https:// dx.doi.org/10.1148/rg.226025128

7. Commission IE. Medical electrical equipment-Part 2-44: Particular requirements for the basic safety and essential performance of X-ray equipment for computed tomography. 2009 [cited 2018 Mar 10]. Available from: <https://webstore. iec.ch/publication/2661>.

8. Dixon RL, Anderson JA, Bakalyar DM, Boedeker K, Boone $J$, Cody $D$, et al. Comprehensive methodology for the evaluation of radiation dose in x-ray computed tomography. Rep AAPM Task Gr. 2010; 111:20740-3846. https://dx.doi. org/10.37206/109

9. McLean ID. Status of computed tomography dosimetry for wide cone beam scanners. International Atomic Energy Agency; 2011 [cited 2018 Mar 10]. Available from: <https:// www-pub.iaea.org/MTCD/Publications/PDF/P1528_web.pdf>.

10. Dixon RL. Restructuring CT dosimetry-A realistic strategy for the future Requiem for the pencil chamber. Med Phys. 2006;33(10):3973-6. https://dx.doi.org/10.1118/1.2336504

11. Brenner DJ, McCollough CH, Orton CG. It is time to retire the computed tomography dose index (CTDI) for CT quality assurance and dose optimization. Med Phys. 2006;33(5):1189-91. https://dx.doi.org/10.1118/1.2173933

12. Mori S, Endo M, Nishizawa K, Tsunoo T, Aoyama T, Fujiwara H, et al. Enlarged longitudinal dose profiles in cone-beam CT and the need for modified dosimetry. Med Phys. 2005;32(4):1061-9. https://dx.doi.org/10.1118/1.1877852

13. Loubele M, Jacobs R, Maes F, Denis K, White S, Coudyzer $W$, et al. Image quality vs radiation dose of four cone beam computed tomography scanners. Dentomaxillofacial Radiol. 2008;37(6):309-18. https://dx.doi.org/10.1259/dmfr/16770531

14. Helmrot E, Thilander-klang A, Sciences H, Carlsson A. Methods for Monitoring patient dose. Radiat Prot Dosimetry. 2010;139(1):303-5. https://dx.doi.org/10.1093/rpd/ncq095

15. Han S, Lee B, Shin G, Choi J, Kim J, Park C, et al. Dose area product measurement for diagnostic reference levels and analysis of patient dose in dental radiography. Radiat Prot Dosimetry. 2012; 150(4):523-31. https://dx.doi.org/10.1093/ $\mathrm{rpd} / \mathrm{ncr} 439$

16. Pauwels R, Beinsberger J, Collaert B, Theodorakou C, Rogers J, Walker A, et al. Effective dose range for dental cone beam computed tomography scanners. Eur J Radiol. 2012;81(2):267-71. https://dx.doi.org/10.1016/j.ejrad.2010.11.028

17. Batista WO, Navarro MVT, Maia AF. Development of a phantom and a methodology for evaluation of depth kerma and kerma index for dental cone beam computed tomography. Radiat Prot Dosimetry. 2013;157(4):543-51. https://dx.doi.org/10.1093/rpd/nct174 
18. Vinicius M, Oliveira L, Otto W, Batista G, Soares MR. Air kerma area product in cone beam computed tomography. 2014;13(3):309-12. http://dx.doi.org/10.9771/cmbio. v13i3.12936

19. Ludlow JB, Walker C. Assessment of phantom dosimetry and image quality of i-CAT FLX cone-beam computed tomography. Am J Orthod Dentofac Orthop. 2013;144(6):802-17. https:// dx.doi.org/10.1016/j.ajodo.2013.07.013

20. Leitz W, Axelsson B, Szendrö G. Computed tomography dose assessment-a practical approach. Radiat Prot Dosimetry. 1995; 57(1-4):377-80. https://dx.doi.org/10.1093/oxfordjournals.rpd. a082564

21. International Atomic Energy Agency. Quality Assurance Programme for Computed Tomography: Diagnostic and Therapy Applications, Human Health Series No. 19, IAEA, Vienna; 2012 [cited 2018 Mar 10]. Available from: <https:// www.iaea.org/publications/8751/quality-assuranceprogramme-for-computed-tomography-diagnostic-andtherapy-applications>.

22. Abuhaimed A, Martin CJ, Sankaralingam M, Gentle DJ, McJury M. An assessment of the efficiency of methods for measurement of the computed tomography dose index (CTDI) for cone beam (CBCT) dosimetry by Monte Carlo simulation. Phys Med Biol. 2014;59(21):6307-26. https:// dx.doi.org/10.1088/0031-9155/59/21/6307

23. Commission IE. Medical electrical equipment-Part 2-44: Particular requirements for the basic safety and essential performance of X-ray equipment for computed tomography. 2009 [cited 2018 Mar 10]. Available from: <https://webstore. iec.ch/publication/24442>.

24. Kim S, Song H, Samei E, Yin FF, Yoshizumi TT. Computed tomography dose index and dose length product for conebeam CT: Monte Carlo simulations of a commercial system. J Appl Clin Med Phys. 2011;12(2):84-95. https://dx.doi. org/10.1120/jacmp.v12i2.3395

25. Abuhaimed A, Martin CJ. Evaluation of coefficients to derive organ and effective doses from cone-beam CT (CBCT) scans: a Monte Carlo study. J Radiol Prot. 2018;38(1):189-206. https://dx.doi.org/10.1088/1361-6498/aa9b9f

26. Geleijns J, Salvadó-Artells M, De Bruin PW, Mather R, Muramatsu Y, McNitt-Gray MF. Computed tomography dose assessment for a $160 \mathrm{~mm}$ wide, 320 detector row, cone beam CT scanner. Phys Med Biol. 2009;54(10):3141-59. https:// dx.doi.org/10.1088/0031-9155/54/10/012

Received on: 17/12/2018 Final version resubmitted on: 15/6/2019

Approved on: 26/7/2019 